\title{
PENGEMBANGAN \\ APLIKASI SISTEM PENDUKUNG KEPUTUSAN UNTUK PENENTUAN PERKIRAAN PRODUKSI AIR MINUM KEMASAN DENGAN METODE FUZZY INFERENCE SYSTEM TSUKAMOTO
}

\author{
Ketut Era Supriadi ${ }^{1}$, I Made Agus Wirawan ${ }^{2}$, I Gede Mahendra Darmawiguna ${ }^{3}$ \\ ${ }^{1}$ Jurusan Pendidikan Teknik Informatika, Universitas Pendidikan Ganesha \\ Singaraja, Indonesia \\ e-mail: dompetberuetz@gmail.com ${ }^{1}$, imade.aguswirawan@undiksha.ac.id ${ }^{2}$, \\ mahendra.darmawiguna@undiksha.ac.id ${ }^{3}$
}

\begin{abstract}
Abstrak
PT Tirta Mumbul Jaya Abadi yaitu salah satu perusahaan air minum di kota Singaraja, masih seringkali mengalami kekeliruan dalam perhitungan seperti jumlah produksi. Perkembangan teori logika fuzzy dapat digunakan untuk memodelkan berbagai sistem, mampu memetakan suatu input kedalam suatu output tanpa mengabaikan faktor-faktor yang ada. Berdasarkan uraian diatas, peneliti mengembangkan Aplikasi Sistem Pendukung Keputusan Untuk Penentuan Perkiraan Produksi Air Minum Kemasan dengan Metode Fuzzy Inference System Tsukamoto di PT. Tirta Mumbul Jaya Abadi. Pengembangan Aplikasi ini dikembangkan dengan menggunakan Metode Fuzzy Inference System Tsukamoto.Hasil dari penelitian ini yaitu berupa Aplikasi Sistem Pendukung Keputusan Untuk Penentuan Perkiraan Produksi Air Minum Kemasan Dengan Metode Fuzzy Inference System Tsukamoto. Seluruh Kebutuhan fungsional aplikasi ini telah berhasil diimplementasikan sesuai dengan rancangannya. Secara umum aplikasi mendapatkan respon sangat baik dilihat dari beberapa hasil pengujian angket yaitu : a) Angket Uji Kesesuaian Proses Aplikasi, b) Angket Penilaian Respon Pengguna Terhadap Aplikasi.
\end{abstract}

Kata kunci : Produksi, Fuzzy, Tsukamoto,SPK.

\begin{abstract}
PT Tirta Mumbul Jaya Abadi, one of the drinking water company in Singaraja city, still often mistaken in calculation such as production amount. The development of fuzzy logic theory can be used to model various systems, able to map an input into an output without ignoring the factors that exist. Based on the description above, the researcher develops Decision Support System Application for Determination of Drinking Water Production of Packaging with Tsukamoto Fuzzy Inference System Method at PT. Tirta Mumbul Jaya Abadi. This application development was developed using the Tsukamoto Fuzzy Inference System Method. The result of this research is in the form of Decision Support System Application For Estimation of Drinking Water Production of Packaging With Fuzzy Inference System Method of Tsukamoto. All functional requirements of this application has been successfully implemented in accordance with the design. In general applications get very good response seen from several test results of the questionnaire are: a) Questionnaire Test Conformity Application Process, b) Questionnaire Assessment User Response Against the Application.
\end{abstract}

Keywords: Production, Fuzzy, Tsukamoto, SPK. 


\section{PENDAHULUAN}

Air adalah sumber kehidupan, tanpa air makhluk hidup tidak dapat bertahan untuk memenuhi kebutuhan hidupnya. Bahkan dapat dipastikan tanpa pengembangan sumber daya air secara konsisten peradaban manusia tidak akan mencapai tingkat yang dinikmati sampai saat ini. Seiring dengan kemajuan teknologi Air Minum Dalam Kemasan merupakan salah satu solusi untuk menjawab permasalahan di atas yaitu produk AMDK dapat langsung diminum karena telah melalui proses produksi yang higienis.

Salah satu perusahaan air minum dalam kemasan di kota Singaraja adalah PT Tirta Mumbul Jaya Abadi , perusahaan ini memproduksi jenis air minum dalam kemasan dalam bentuk gelas, botol dan galon. Dalam kegiatan produksinya, PT Tirta Mumbul Jaya Abadi masih menggunakan perhitungan manual dengan mempertimbangkan jumlah persediaan dan jumlah permintaan, namun seringkali mengalami kekeliruan dalam perhitungan seperti jumlah produksi yang melebihi stok gudang atau kekurangan persediaan barang jumlah ketika permintaan naik. Sesuai dengan permasalahan yang ditemukan di lapangan dan dari hasil observasi yang di dapatkan,Maka penulis memutuskan untuk mengembangkan sebuah aplikasi dimana aplikasi tersebut dapat membantu menentukan jumlah produksi yang lebih relevan dan sebagai pertimbangan seorang pelaku produksi untuk menentukan berapa jumlah barang yang harus di produksi dengan teori logika fuzzy.

Perkembangan teori logika fuzzy menunjukkan bahwa logika fuzzy dapat digunakan untuk memodelkan berbagai sistem, mampu memetakan suatu input kedalam suatu output tanpa mengabaikan faktor-faktor yang ada. Oleh karena itu logika fuzzy dalam teori himpunan fuzzy dapat digunakan solusi alternatif untuk mengatasi kekurangan model dalam memperkirakan jumlah produksi. [1]

Metode logika fuzzy, telah digunakan untuk mengembangkan sistem pendukung dan perkembangan ilmu pengetahuan, kesadaran masyarakat terhadap kesehatan terutama dalam pemenuhan kebutuhan air bersih untuk minum juga semakin tinggi. Sementara dilain pihak persediaan air tanah yang selama ini menjadi sumber utama air minum telah mengalami pencemaran. Produk air minum yang dikenal sebagai air minum dalam kemasan

keputusan untuk menentukan jumlah produksi barang dalam penelitian yang berjudul Penerapan Metode Algoritma Fuzzy Mamdani pada Aplikasi SPK Penentuan Jumlah Produksi Barang Cv.Kurnia Alam di Jepara. Penelitian ini menguraikan tentang sistem pendukung keputusan yang mengolah data dengan metode Mamdanidan akan menampilkan keluaran berupa jumlah barang yang akan diproduksi. [2]

Berdasarkan uraian diatas, peneliti berharap dapat memberi kontribusi berharga bagi perusahaan, khususnya dalam memperkirakan jumlah produksi air minum dalam kemasan menggunakan Sistem Inferensi Fuzzy Metode Tsukamoto dengan mengembangkan sebuah penelitian yang berjudul Aplikasi Sistem Pendukung Keputusan Untuk Penentuan Perkiraan Produksi Air Minum Kemasan dengan Metode Fuzzy Inference System Tsukamoto di PT. Tirta Mumbul Jaya Abadi.

\section{KAJIAN TEORI}

\section{A. PT. TIRTA MUMBUL JAYA ABADI}

PT. Tirta Mumbul Jaya Abadi merupakan perusahaan penghasil produk Air Minum Dalam Kemasan (AMDK) yang diresmikan oleh Bapak Bupati Buleleng pada tanggal 25 Agustus 2003, sekaligus mendukung kesiapan Kabupaten Buleleng sebagai tuan rumah Porda Bali ke VI. Selanjutnya secara organisatoris pada tanggal 1 September 2003 dibentuklah suatu unit usaha air minum "Yeh Buleleng" dibawah kendali Direksi PDAM Kabupaten Buleleng.

PT. Tirta Mumbul Jaya Abadi merupakan perusahaan penghasil produk Air Minum Dalam Kemasan (AMDK) merek 'Yeh Buleleng' yang memiliki permasalahan 
dalam kegiatan produksi yang menyebabkan perkiraan jumlah produksi tidak sesuai dengan kebutuhan. Adapun permasalahan - permasalahan yang di dapatkan pada saat observasi di lapangan dengan Kabag Produksi bapak Gede Adi Kurniawan adalah sebagai berikut :

1. Penjadwalan produksi masih manual sehingga hasil dari produksi terkadang tidak sesuai dengan yang dibutuhkan.

2. Produksi yang tidak terkontrol yang menyebabkan hasil dari produksi melebihi kapasitas gudang.

3. Jumlah Produksi terkadang tidak sesuai dengan jumlah permintaan

\section{B. Sistem Pendukung Keputusan}

Sistem Pendukung Keputusan

(Decision Support Sistem) merupakan suatu sistem yang memanfaatkan dukungan komputer dalam proses pengambilan keputusan. SPK merupakan suatu sistem yang interaktif,yang membantu pengambil keputusan melalui penggunaan data dan model-model keputusan untuk memecahkan masalah yang sifatnya semi terstruktur maupun yang tidak terstruktur. [3]

\section{Logika Fuzzy}

Teori himpunan logika fuzzy di kembangkan oleh Professor Lofti A. Zadeh pada tahun 1965.la berpendapat bahwa logika benar dan salah dari logika booleanlkonvensional tidak dapat mengatasi masalah gradasi yang berada pada dunia nyata.Untuk mengatasi masalah gradasi yang tidak terhingga tersebut, Zadeh mengembangkan sebuah himpunan fuzzy. Tidak seperti logika boolean, logika fuzzy mempunyai nilai yang kontinu. Fuzzy dinyatakan dalam derajat dari suatu keanggotaan dan derajat dari kebenaran. Oleh sebab itu sesuatu dapat dikatakan sebagian benar dan sebagian salah pada waktu yang sama.

Sistem fuzzy dikenal beberapa metode penalaran, antara lain : metode Tsukamoto, metode Mamdani dan metode Sugeno.

\section{PHP}

\section{PHP (Personal Home Page)} merupakan bahasa berbentuk skrip yang ditempatkan dalam server dan diproses di server.Hasilnya yang dikirimkan ke client, tempat pemakai menggunakan browser. Kelahiran PHP bermula saat Rasmus Lerdorf memebuat sejumlah skrip Perl yang dapat mengamati siapa saja yang melihatlihat daftar riwayat hidupnya, yakni pada tahun 1994.Skrip-skrip ini selanjutnya dikemas menjadi tool yang disebut "Personal Home Page". Paket inilah yang menjadi cikal bakal pemrograman dapat menempelkan kode terstruktur di dalam tag HTML, yang menarik kode PHP juga bisa berkomunikasi dengan database dan melakukan perhitungan-perhitungan yang komples. [4]

\section{METODOLOGI}

\section{A. Analisis Masalah dan Usulan Solusi}

Berdasarkan analisis yang peneliti lakukan, terdapat permasalahan yang terjadi di salah satu perusahaan air minum dalam kemasan di kota Singaraja adalah PT Tirta Mumbul Jaya Abadi, perusahaan ini memproduksi jenis air minum dalam kemasan dalam bentuk gelas, botol dan galon. Dalam kegiatan produksinya, PT Tirta Mumbul Jaya Abadi masih menggunakan perhitungan manual dengan mempertimbangkan jumlah persediaan dan jumlah permintaan, namun seringkali mengalami kekeliruan dalam perhitungan seperti jumlah produksi yang melebihi stok gudang atau kekurangan persediaan barang jumlah ketika permintaan naik. Oleh karena itu logika fuzzy dalam teori himpunan fuzzy dapat digunakan solusi alternatif untuk mengatasi kekurangan model dalam memperkirakan jumlah produksi. [1]

Sesuai dengan permasalahan yang ditemukan di lapangan dan dari hasil observasi yang di dapatkan, maka penulis memutuskan untuk mengembangkan sebuah aplikasi dimana aplikasi tersebut dapat membantu menentukan jumlah produksi yang lebih relevan dan sebagai pertimbangan seorang pelaku produksi untuk menentukan berapa jumlah barang 
yang harus di produksi dengan teori logika fuzzy.

B. Analisis Perangkat Lunak

1. Kebutuhan Perangkat Lunak

Berdasarkan analisis yang dilakukan, perangkat lunak yang dibutuhkan dalam Pengembangan Aplikasi Sistem Pendukung Keputusan Untuk Penentuan Perkiraan Produksi Air Minum Kemasan Dengan Metode Fuzzy Inference System Tsukamoto ini adalah:

a. Dreamweaver sebagai editor script php untuk merancang aplikasi web base

b. Xampp 1.8.3

c. Photoshop CS4

2. Tujuan Pengembangan Perangkat Lunak Pengembangan Aplikasi Sistem

Pendukung Keputusan Untuk Penentuan Perkiraan Produksi Air Minum Kemasan Dengan Metode Fuzzy Inference System Tsukamoto ini diharapkan mampu memenuhi proses-proses fungsional sebagai berikut.

1. Aplikasi dapat menampilkan antarmuka halaman login administrator

2. Aplikasi dapat menampilkan antarmuka halaman utama

3. Aplikasi dapat menampilkan antarmuka sidebar untuk masingmasing menu

4. Aplikasi dapat menampilkan antarmuka olah data dari setiap manipulasi proses

5. Aplikasi dapat menampilkan Prediksi Produksi Air Minum Dalam Kemasan berdasarkan Data permintaan dan jumlah stok

6. Aplikasi dapat menampilkan antarmuka cetak laporan produksi

7. Aplikasi dapat mencetak laporan bulanan untuk hasil produksi.

8. Aplikasi dapat menampilkan antarmuka edit profil admin

9. Aplikasi dapat menampilkan antarmuka data user saat user login berstatus admin.

10. Aplikasi dapat menampilkan antarmuka tambah data user saat user login berstatus admin.
Sementara untuk kebutuhan non fungsional diharapkan memenuhi prosesproses sebagai berikut:

1. Aplikasi dapat berjalan pada perangkat smartphone, PC, notebook.

1. Aplikasi dibuat dengan user friendly agar menarik bagi pengguna aplikasi.

3. Masukan dan Keluaran Perangkat Lunak Pengembangan Aplikasi Sistem Pendukung Keputusan Untuk Penentuan Perkiraan Produksi Air Minum Kemasan Dengan Metode Fuzzy Inference System Tsukamoto menerima input berupa data produksi, sedangkan keluaran (output) berupa informasi perkiraan produksi dan informasi data produksi per bulan.

4. Model Fungsional Perangkat Lunak

Dalam pengembangan aplikasi ini, peneliti merancangan sebuah arsitektur Pengembangan Aplikasi Sistem Pendukung Keputusan Untuk Penentuan Perkiraan Produksi Air Minum Kemasan Dengan Metode Fuzzy Inference System Tsukamoto, yaitu semua perangkat terhubung dengan koneksi internet.

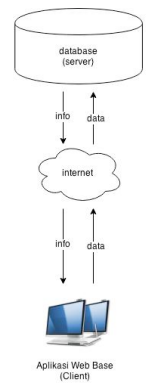

Gambar 1. Arsitektur Sistem aplikasi sistem pendukung keputusan untuk penentuan perkiraan produksi air minum kemasan

\section{a. DFD (Data Flow Diagram)}

Data Flow Diagram (DFD) adalah diagram yang menggunakan notasi simbol untuk menggambarkan arus data sistem.[5] Berikut ini akan dijabarkan mengenai rancangan Pengembangan Aplikasi Sistem Pendukung Keputusan Untuk Penentuan Perkiraan Produksi Air Minum Kemasan Dengan Metode Fuzzy Inference System Tsukamoto di PT. Tirta Mumbul Jaya Abadi, 
beserta hubungan entitas luarnya secara detail menggunakan Diagram Konteks dan Diagram Arus Data Level 1.

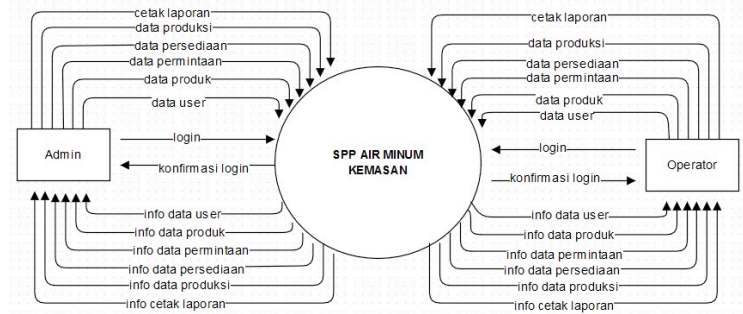

Gambar 2. Diagram Arus Data Level 1

\section{b. Database}

Aplikasi ini terintegrasi dengan database yang berada di dalam komputer server. Database akan disimpan dalam bentuk MySQL database. Rancangan tabel dari aplikasi ini dapat dilihat pada gambar berikut.

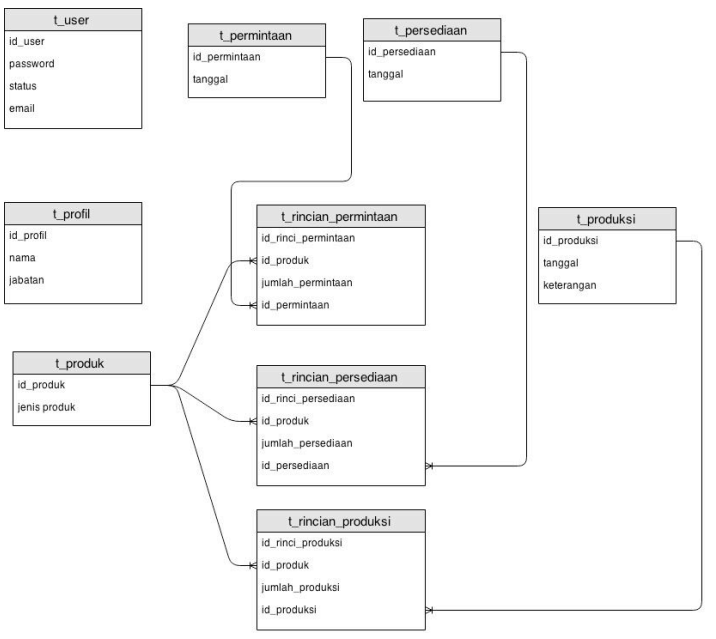

Gambar 3. Database Sistem Aplikasi Sistem Pendukung Keputusan Untuk Penentuan Perkiraan Produksi Air Minum Kemasan Dengan Metode Fuzzy Inference System Tsukamoto di PT. Tirta Mumbul Jaya Abadi

C. Perancangan Perangkat Lunak

1. Batasan Perancangan Perangkat Lunak Adapun batasan masalah pada penelitian ini adalah Aplikasi Sistem Pendukung Keputusan Untuk Penentuan Perkiraan Produksi Air Minum Kemasan Dengan Metode Fuzzy Inference System Tsukamoto di PT. Tirta Mumbul Jaya Abadi.
2. Perancangan Antarmuka Perangkat Lunak Perancangan antarmuka perangkat lunak merupakan proses merancang antarmuka yang akan digunakan untuk berinteraksi antara pengguna dengan perangkat lunak yang akan dikembangkan. Perancangan yang dibuat bersifat user friendly dimana bertujuan agar pengguna merasa tertarik, nyaman, dan mudah dalam menggunakannya.

a. Perancangan Antarmuka login web base

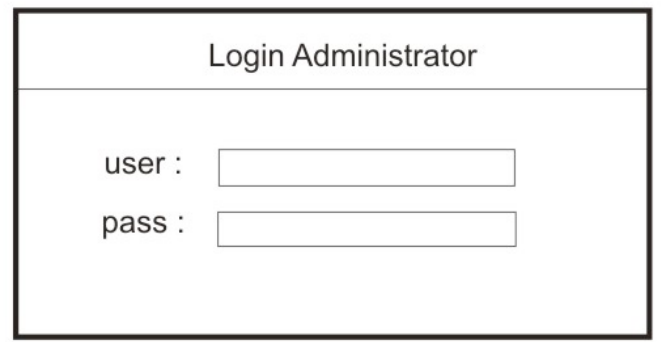

Gambar 4. Perancangan Antarmuka login web base

b. Perancangan Antarmuka Menu Utama aplikasi web base

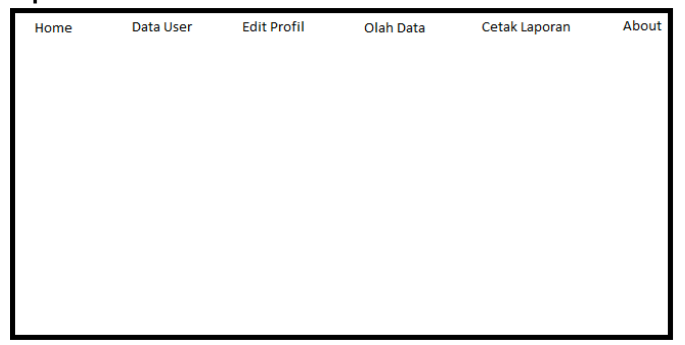

Gambar 5. Perancangan Antarmuka Menu Utama aplikasi web base

c. Perancangan Antarmuka Data User

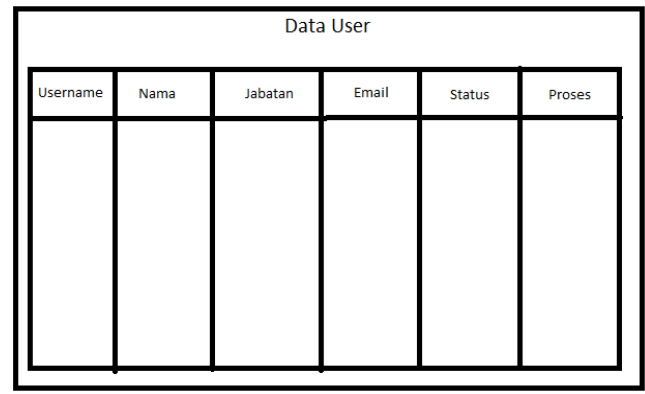

Gambar 6. Perancangan Antarmuka Data User 
d. Perancangan Antarmuka Tambah User

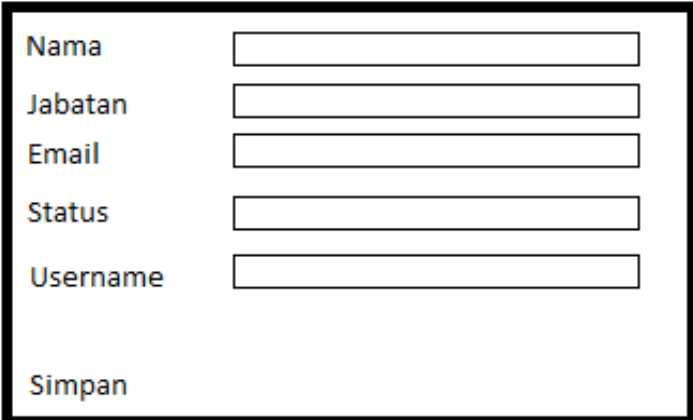

Gambar 7. Perancangan Antarmuka Tambah User

e. Perancangan Antarmuka Edit Profil User

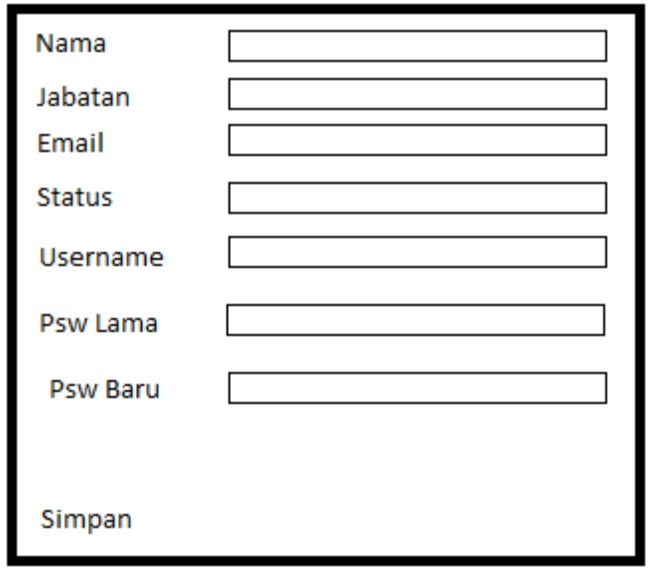

Gambar 8. Perancangan Antarmuka Edit Profil User

\section{f. Perancangan Antarmuka Olah Data}

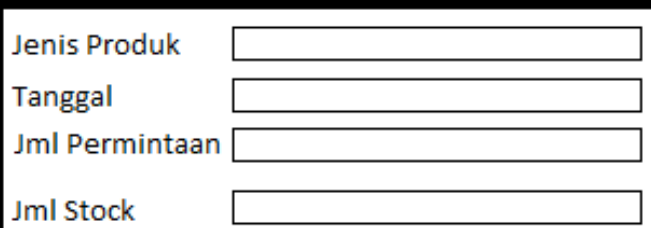

Hitung

Gambar 9. Perancangan Antarmuka Olah Data g. Perancangan Antarmuka Cetak Laporan

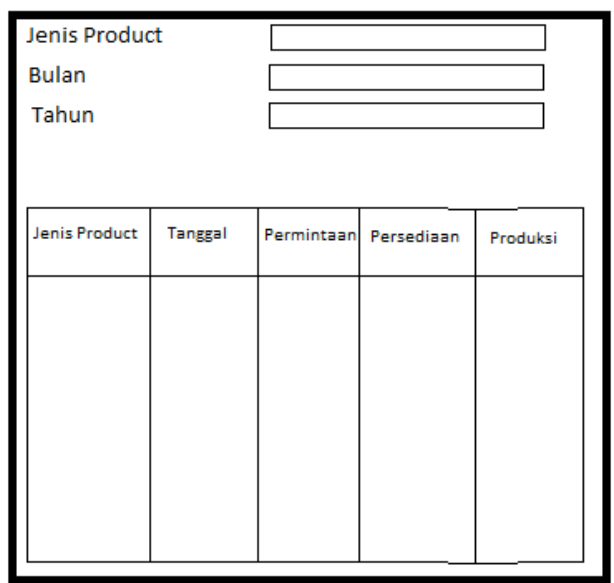

Gambar 10. Perancangan Antarmuka Cetak Laporan

h. Perancangan Antarmuka About

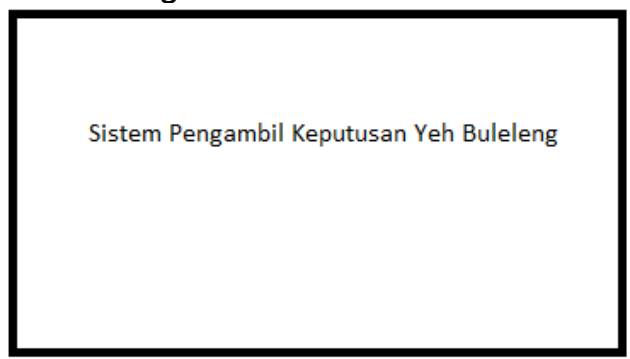

Gambar 11. Perancangan Antarmuka About

\section{PEMBAHASAN}

A. Implementasi Perangkat Lunak

1. Lingkungan Implementasi Perangkat

Lunak

Perangkat lunak yang digunakan dalam mengimplementasikan Aplikasi Sistem Pendukung Keputusan Untuk Penentuan Perkiraan Produksi Air Minum Kemasan Dengan Metode Fuzzy Inference System Tsukamoto di PT. Tirta Mumbul Jaya Abadi berbasis Web yaitu sebagai berikut
1. $X A M P P$
2. Dreamweaver 
Adapun lingkungan perangkat kerasnya yaitu sebuah laptop dengan spesifikasi sebagai berikut.

a. Monitor 14,1 inchi dengan resolusi $1366 \times 768$

b. Memori 4 GB RAM dan harddisk 500 GB

C. Prosesor Intel ${ }^{\circledR}$ Core $^{\mathrm{TM}}$ i5 $2.5 \mathrm{Ghz}$

2. Implementasi Arsitektur Perangkat Lunak

Implementasi antarmuka dilakukan sesuai dengan rancangan antarmuka yang telah dibuat sebelumnya.

a. Implementasi Antarmuka Login

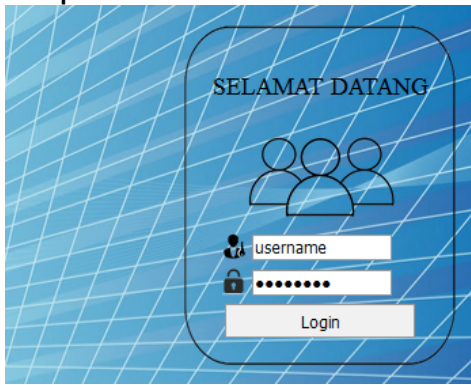

Gambar 12. Implementasi Antarmuka Login

b. Implementasi Antarmuka Menu Utama

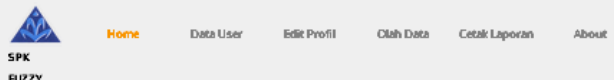

Sistem Pengambil Keputusan Yeh Buleleng

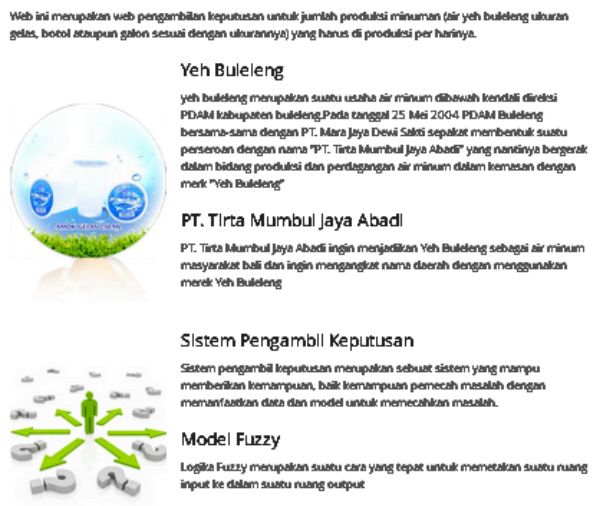

Gambar 13. Implementasi Antarmuka Beranda c. Implementasi Antarmuka Data User

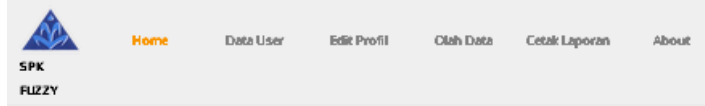

Data User

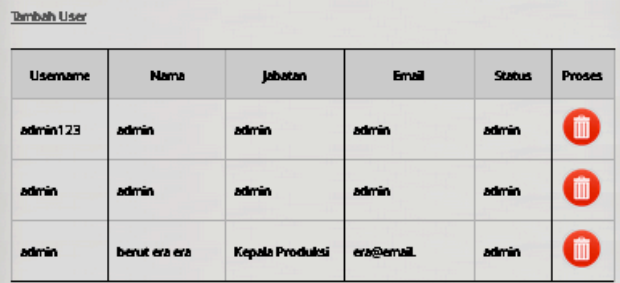

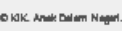

(580 0

Gambar 14. Implementasi Antarmuka Data User (Menghapus user)

d. Implementasi Antarmuka Tambah User

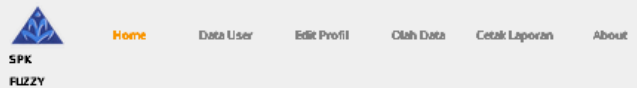

Gambar 15. Implementasi Antarmuka Tambah User 
e. Implementasi Antarmuka Edit Profil User

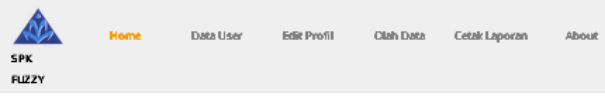
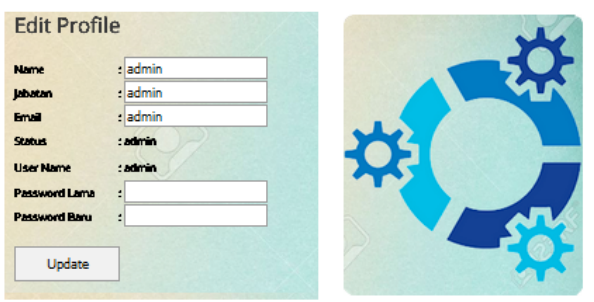

Ook mentom num

( 800

Gambar 16. Implementasi Antarmuka Edit Profil User

f. Implementasi Antarmuka Olah Data

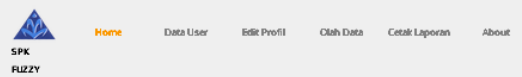

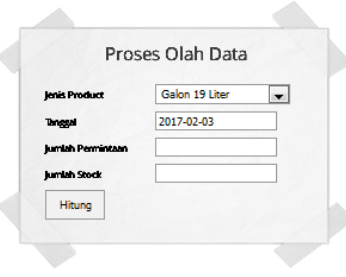

ove numasm

(9800

Gambar 17. Implementasi Antarmuka Olah Data

g. Implementasi Antarmuka Cetak Laporan
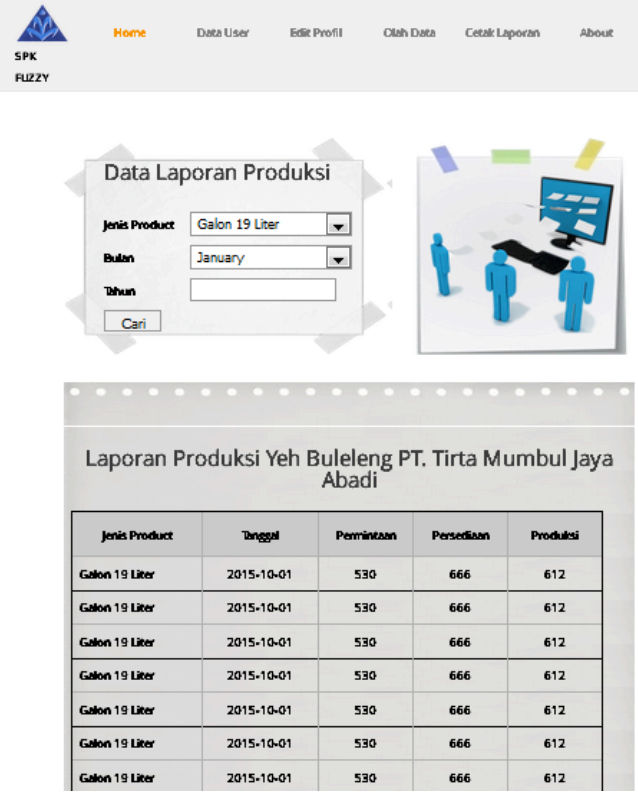

Gambar 18. Implementasi Antarmuka Laporan

h. Implementasi Antarmuka About

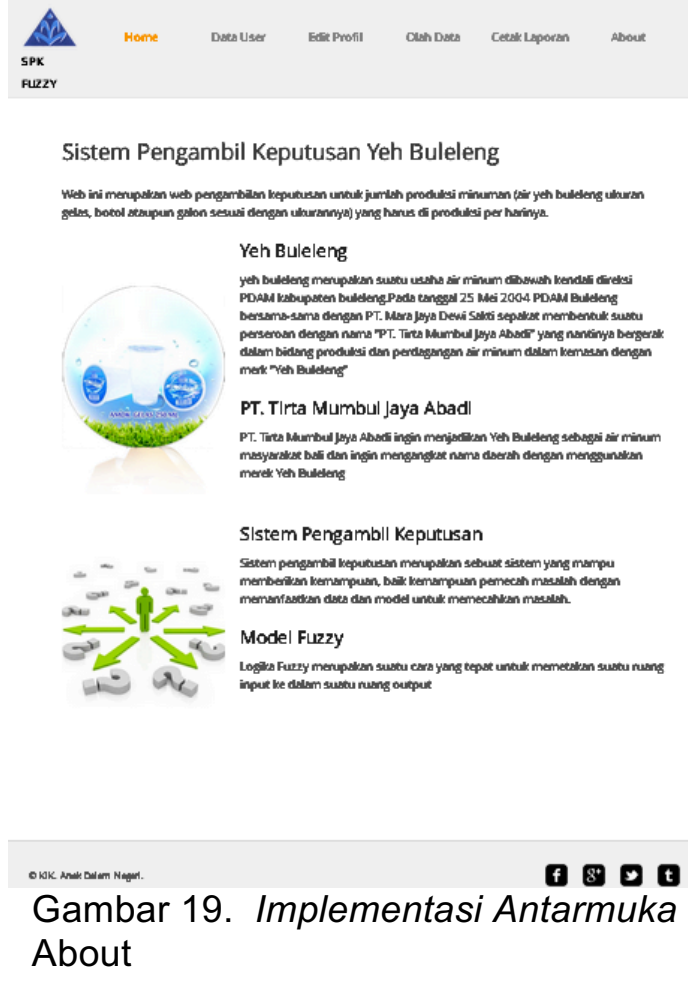

B. Pengujian Perangkat Lunak

1. Tujuan Pengujian Perangkat Lunak

Tujuan pengujian Aplikasi Sistem Pendukung Keputusan Untuk Penentuan Perkiraan Produksi Air Minum Kemasan dengan Metode Fuzzy Inference System Tsukamoto di PT Tirta Mumbul Jaya Abadi, yaitu:

a. Menguji kebenaran proses Aplikasi Sistem Pendukung Keputusan Untuk Penentuan Perkiraan Produksi Air Minum Kemasan dengan Metode Fuzzy Inference System Tsukamoto di PT Tirta Mumbul Jaya Abadi.

b. Menguji respon dari pengguna setelah menggunakan Aplikasi Sistem Pendukung Keputusan Untuk Penentuan Perkiraan Produksi Air Minum Kemasan dengan Metode Fuzzy Inference System Tsukamoto di PT Tirta Mumbul Jaya Abadi.

2. Perancangan Kasus Uji Pengujian Perangkat Lunak 
Pengujian ini dilakukan untuk mengetahui respon pengguna setelah menggunakan Aplikasi Sistem Pendukung Keputusan Untuk Penentuan Perkiraan Produksi Air Minum Kemasan dengan Metode Fuzzy Inference System Tsukamoto di PT Tirta Mumbul Jaya Abadi. Selanjutnya hasil dari penggunaan aplikasi akan digambarkan dalam Angket Penilaian Respon Pengguna Terhadap Aplikasi Sistem Pendukung Keputusan Untuk Penentuan Perkiraan Produksi Air Minum Kemasan dengan Metode Fuzzy Inference System Tsukamoto di PT Tirta Mumbul Jaya Abadi.

\section{Pelaksanaan Pengujian Perangkat Lunak}

Untuk respon pengguna Aplikasi

Sistem Pendukung Keputusan Untuk Penentuan Perkiraan Produksi Air Minum Kemasan dengan Metode Fuzzy Inference System Tsukamoto di PT Tirta Mumbul Jaya Abadi dilakukan pada pengguna staf perusahaan PT Tirta Mumbul Jaya Abadi.

\section{Evaluasi Hasil Pengujian Perangkat Lunak}

Berdasarkan pengujian yang telah dilakukan untuk uji kasus black box testing Aplikasi Sistem Pendukung Keputusan Untuk Penentuan Perkiraan Produksi Air Minum Kemasan dengan Metode Fuzzy Inference System Tsukamoto di PT Tirta Mumbul Jaya Abadi, semua proses mulai dari saat pertama kali aplikasi dijalankan sampai dengan selesai keluar dari aplikasi berfungsi dengan baik. Hasil pengujian kesesuaian proses tersebut, diperoleh hasil semua proses sesuai atau berhasil berjalan dengan baik. Semua tombol fungsi pada aplikasi berjalan sesuai dengan yang direncanakan sebelumnya.

\section{SIMPULAN}

Berdasarkan hasil analisis, implementasi dan pengujian pada penelitian pengembangan Aplikasi Sistem Pendukung Keputusan Untuk Penentuan Perkiraan Produksi Air Minum Kemasan dengan Metode Fuzzy Inference System Tsukamoto di PT Tirta Mumbul Jaya Abadi, dapat ditarik kesimpulan sebagai berikut.
1. Perancangan Aplikasi Sistem

Pendukung Keputusan Untuk

Penentuan Perkiraan Produksi Air Minum Kemasan dengan Metode Fuzzy Inference System Tsukamoto di PT Tirta Mumbul Jaya Abadi mengguakan DFD (Data Flow Diagram) dan Database .

2. Aplikasi Sistem Pendukung Keputusan Untuk Penentuan Perkiraan Produksi Air Minum Kemasan dengan Metode Fuzzy Inference System Tsukamoto di PT Tirta Mumbul Jaya Abadi telah berhasil diimplementasikan sesuai dengan rancangan yang telah dibuat sebelumnya.

3. Hasil dari pengujian pengujian blackbox testing Aplikasi Sistem Pendukung Keputusan Untuk Penentuan Perkiraan Produksi Air Minum Kemasan dengan Metode Fuzzy Inference System Tsukamoto di PT Tirta Mumbul Jaya Abadi mendapat respon baik.

Saran untuk pengembangan aplikasi selanjutnya adalah agar dapat ditambahkan fitur-fitur tambahan selain fitur yang sudah dicantumkan dalam sistem.

\section{REFERENSI}

[1] Karwowski, W. and Evans, G.W. 1986. Fuzzy Concepts in Production Management Research - A Review. International Journal of Production Research

[2] Widiyantoro, Andreas.2013.Penerapan Metode Aloritma Fuzzymamdani pada Aplikasi SPK Penentuan Jumlah Produksi Barang Cv.Kurnia Alam di Jepara.

[3] Rahman, A. (2011). Sisem Penunjang Keputusan Dalam Penentuan Penerima Kredit Mobil Berbasis Analitical Hierarchy Proses(AHP). Banjarmasin: STMIK Banjarbaru.

[4] Kadir, Abdul. 2003. Dasar Pemrograman Web Dinamis Menggunakan PHP. Yogyakarta: ANDI.

[5] Hartono, Jogiyanto. 1999. Analisis \& Desain Sistem Informasi. Yogyakarta: Penerbit Andi. 